Article history

Received Augt 1, 2018

Accepted Nov 15, 2018

\title{
EVALUASI DAN PENGEMBANGAN ALTERNATIF DESAIN ANTARMUKA E-CAMPUS STIKOM AMBON
}

\author{
Amran Suatkab ${ }^{1}$, Harry Budi Santoso ${ }^{2}$ \\ ${ }^{1}$ Teknik Informatika, Universitas AMIKOM Yogyakarta \\ ${ }^{2}$ Fakultas Ilmu Komputer, Universitas Indonesia \\ Email :ran.suatkab@gmail.com, harrybs@,cs.ui.ac.id
}

\begin{abstract}
E-Campus is a support media of administration and academic activities system that used to improve the effectiveness and efficiency of campus activities. However, e-Campus developed by a private company to meet the needs in general, which means it is not created to the specific needs of the campus that impact on campus administration and academic activities such as unused features or those that unrelated to campus activities. Furthermore, for students and lecturers, there are parts of the form that are not complete, and so forth. Evaluation with e-Campus system is done by multi method which consist of usability test, that is observing respondent difficulties in utilizing function / e-Campus feature specifically, and system usability scale to assess system as a whole. The results show that none of the scenarios were successfully resolved without help (hint). The completion rate for tasks 13 and 18 is $0 \%$ of all users and furthermore, not all tasks were completed on time. The main problem lies in the page view, toolbar, navigation system and incomplete pages. The e-campus prototype was built based on Shneiderman's 8 Golden Rules of Interface Design with considerations on inputs from the evaluation process..
\end{abstract}

Keywords: SUS, Usability, E-Campus, Prototype, Shneiderman's

\begin{abstract}
Abstrak
E-Campus adalah sebuah media pendukung sistem administrasi dan kegiatan akademis yang digunakan untuk meningkatkan efektifitas dan efisiensi kegiatan kampus. Namun, e-Campus dikembangkan oleh sebuah perusahaan swasta untuk memenuhi kebutuhan secara umum, yang artinya tidak dibuat untuk memenuhi semua kebutuhan kampus secara spesifik yang berdapampak pada kegiatan administrasi dan akademik kampus seperti fitur-fitur yang tidak terpakai, tidak berhubungan dengan kegiatan kampus. Lebih lanjut lagi, bagi mahasiswa dan dosen, terdapat bagian formulir yang tidak lengkap, dan lain sebagainya. Evaluasi pada sistem e-Campus dilakukan dengan menerapkan multi metode yang terdiri dari uji usability dengan mengamati kesulitan responden dalam memanfaatkan fungsi/fitur e-Campus secara khusus dan juga system usability scale untuk menilai sistem secara menyeluruh. Hasil menujukkan tidak satupun skenario yang berhasil diselesaikan tanpa bantuan (hint). Lebih lanjut completion rates untuk task 13 dan 18 adalah $0 \%$ dari jumlah pengguna. Selain itu, semua task diselesaikan peserta tidak on-time. Permasalahan utama terdapat pada tampilan halaman, toolbar, sistem navigasi, dan juga halaman yang tidak lengkap. Selanjutnya, prototipe e-Camapus dibangun berdasarkan Shneiderman's 8 golden rules of interface design rules shneiderman dan mempertimbangkan masukan dari tahapan evaluasi
\end{abstract}

Kata Kunci: SUS, Usability, E-Campus, Prototipe, Shneiderman's Eight Golden Rules 


\section{PENDAHULUAN}

Pemanfaatan komputer telah dilakukan di berbagai bidang untuk membantu pekerjaan manusia (Sudarmawan \& Ariyus, 2007). Hal itu menciptakan berbagai terobosan baru serta mendorong akademisi dan peneliti untuk terus menerus melakukan penelitian baik itu pengembangan teknologi maupun dibidang interaksi manusia dengan komputer (humancomputer interaction) seperti pengembangan web tool dibidang pemerintahan (Jayanti, 2017), pembuatan sistem prediksi dibidang kesehatan (Praningku \& Budi, 2017), melakukan evaluasi akademik dibidang pendidikan (Mustafa, Ramadhan, \& Thenata, 2017), dan lain sebagainya.

STIKOM Ambon sebagai kampus yang mengedepankan pemanfaatan teknologi sistem informasi dan interaksi manusia-komputer telah meningkatkan kegiatan sistem administrasi dan pembelajaran dengan menerapkan e-Campus ${ }^{\mathrm{TM}}$ sebagai media pendukung sistem administrasi dan kegiatan pembelajaran untuk meningkatkan efektifitas dan efisiensi kegiatan kampus. Namun, e-Campus ${ }^{\mathrm{TM}}$ yang digunakan adalah produk komersil yang didesain untuk memenuhi kebutuhan standar kampus secara umum. Dengan kata lain, produk ini tidak didesain sesuai kebutuhan kampus tertentu. Hal ini berdampak langsung pada kegiatan administrasi dan pembelajaran kampus STIKOM Ambon, diantaranya terdapat fitur-fitur yang tidak terpakai/ tidak berhubungan dengan kegiatan kampus STIKOM Ambon. Selain itu, bagi pengguna baik itu mahasiswa maupun dosen menilai terdapat form-form yang tidak lengkap ataupun sulit digunakan.

\section{Merancang,} membangun,

dan mengembangkan sebuah aplikasi ataupun website harus memenuhi standar kebutuhan dasar pengguna, selain itu masukan ataupun pendapat para pengguna harus dipertimbangkan baik itu dari segi konten, kelengkapan fitur, serta user interface yang baik agar dapat menjamin user experience yang maksimal. Misalnya, mengenai pengembangan sebuah aplikasi pembelajaran bahasa arab (Santoso \& Fitriansyah, 2017). Mereka mengajukan solusi sebuah metode baru pembelajaran bahasa arab dengan mengimplementasi aplikasi pembelajaran mobile sehingga orang-orang dapat belajar dengan mudah, dimanapun dan kapanpun. Hasil evaluasi berupa rekomendasi diantaranya rekomendasi materi secara umum, kosa kata dan grammar.
Penelitian tentang produk lainnya dilakukan dengan menilai kualitas informasi website (Davis \& Jiang, 2015). Mereka menginvestigasi dan mengkritisi beberapa website yang menyediakan informasi type-2 diabetes mellitus (T2DM). Permasalahan usability disetiap website dipaparkan. Temuan dari studi ini sangat penting untuk pengembangan kedepannya sehingga pengguna dapat memiliki user experience yang baik di website-website informasi T2DM dan juga mendapat informasi yang relevant dan berguna bagi mereka.

Hasil evaluasi akan berbeda untuk setiap contoh kasus yang berbeda karena bisa mencakup tampilan (user interface), kelengkapan fitur/fungsi, konten, dan lain sebagainya, tanpa terkecuali e-Campus ${ }^{\mathrm{TM}}$ yang dirancang untuk kebutuhan standar umum kampus \& telah digunakan beberapa kampus di Indonesia, misalnya STIKOM Ambon. Kembali ke tujuan STIKOM Ambon yang mengedepankan pemanfaatan teknologi dalam kegiatan administrasi dan pembelajaran, maka evaluasi terhadap produk e-Campus ${ }^{\mathrm{TM}}$ yang sedang digunakan harus dilakukan guna mendapatkan rekomendasi pengembangan aplikasi e-campus yang mencakup fitur, konten dan juga user interface.

\section{METODE PENELITIAN}

Bagian ini memuat langkah-langkah dan metode yang digunakan dalam penelitian ini yang terdiri dari tahapan evaluasi hingga pembuatan prototipe website (e-Campus).

\subsection{Evaluasi E-Campus}

Tujuan dilakukannya evaluasi pada adalah agar dapat mengidentifikasi kelemahankelemahan agar dapat menjadi masukan untuk pengembangan/perbaikan e-Campus ${ }^{\mathrm{TM}}$ sehingga peran/fungsi e-Campus ${ }^{\mathrm{TM}}$ bisa secara maksimal mendukung kegiatan akademis dan juga administrasi kampus secara online.

\subsection{Uji Usability}

Tujuan umum dari pengujian usability antara lain menetapkan dasar standar performansi, menetapkan dan memvalidasi ukuran (parameter) performa, dan mengidentifikasi potensi permasalahan desain agar segera ditangani dalam rangka meningkatkan efisiensi, produktifitas, dan kepuasan pengguna. Lebih mendetail, tujuan uji usability antara lain: 
1. Untuk mengukur inkonsistensi desain dan area masalah usabilitas pada antarmuka maupun konten seperti masalah navigasi, masalah presentasi, ataupun masalah kontrol (toolbar).

2. Menguji aplikasi atau website pada kondisi yang terkontrol dengan pengguna yang representatif.

3. Mengetahui batas/dasar performa pengguna dan level kepuasan pengguna terhadap antarmuka pengguna untuk evaluasi usabilitas di masa yang akan datang.

Lebih detail, fasilitator akan mengamati, menilai, dan membuat catatan untuk setiap aksi yang dilakukan oleh peserta saat menyelesaikan task. Berikut adalah daftar task scenario yang diujikan:

1. Telusuri Info Pengumuman Kampus.

2. Telusuri Info Biaya Semester.

3. Telusuri Info jadwal perkuliahan.

4. Mengakses fitur pencarian.

5. Mengakses fitur bantuan.

6. Pengisian KRS.

7. Cetak KRS.

8. Pengisian komentar.

9. Mengakses Info KHS.

10.Mengakses transkip.

11. Mengakses Info IPK.

12.Mencetak KHS.

13.Pengisian form pengajuan proposal.

14.Mengakses jadwal kegiatan proposal.

15.Mengakses jadwal, laporan dan rekap siding.

16. Cetak data siding.

17. Download data siding.

18.Pengajuan tempat PKL.

19. Mengakses informasi kelompok PKL.

20.Mengakses info rekapitulasi per matakuliah.

21.Mengakses info rekapitulasi absensi.

\subsection{System Usability Scale}

Agar dapat mendukung evaluasi uji usability maka dilakukan sebuah peniliaian secara subjektif dengan sebuah post-kuesioner menggunakan metode system usability scale (SUS). SUS adalah sebuah skala yang memberikan sebuah gambaran penilian subjektif pada uji usability. SUS menggunakan skala likert. Pada setiap item yang dinilai, para responden akan memberikan penilaian kesetujuan/ ketidaksetujuan dengan statement pada skala 5, yaitu: sangat tidak setuju, tidak setuju, netral, setuju, dan sangat setuju.

Setiap poin/item yang diajukan kepada responden dipilih dapat mewakili berbagai aspek usability sebuah sistem seperti kebutuhan dukungan, kompleksitas antarmuka, dan lain lain (Brooke Et.al, 1996). Sepuluh poin penilaian subjektif yang diajukan pada peserta adalah sebagai berikut:

1. Akan sering menggunakan website ini.

2. Website terlalu kompleks.

3. Website mudah digunakan.

4. Butuh bantuan orang lain agar dapat menggunakan website.

5. Berbagai fungsi di website terintegrasi dengan baik.

6. Terdapat banyak inkonsistensi di website.

7. Kebanyakan orang akan dengan mudah menggunakan website ini.

8. Website tidak praktis.

9. Sangat yakin dalam menggunakan website ini.

10.Butuh banyak belajar agar dapat menggunakan website ini dengan baik.

Untuk dapat membandingkan uji usability dengan post-task overall questionaries maka dibutuhkan skor SUS. Skor SUS merupakan angka yang merepresentasikan kombinasi nilai menyeluruh terhadap system yang diuji.

Skor minimal nilai SUS adalah 0 dan skor maksimal nilai SUS adalah 100. Skor SUS bergantung pada distribusi skor setiap item. Distribusi skor SUS berada pada range 0 hingga 4. Untuk item 1,3,5,7, dan 9 distribusi skornya adalah $0-4$, sedangkan distribusi skor untuk item 2,4,6,8, dan 10 adalah $4-0$. Distribusi/kontribusi skor SUS dapat dilihat pada Tabel berikut ini.

Tabel 1. Distribusi dan aturan skor system usability scale

\begin{tabular}{|c|c|c|c|c|c|}
\hline \multirow{2}{*}{ No. Soal } & \multicolumn{5}{|c|}{$\begin{array}{c}\text { Distribusi Skor berdasarkan } \\
\text { Opsi Jawaban }\end{array}$} \\
\cline { 2 - 6 } & STS & TS & N & S & SS \\
\hline $1,3,5,7,9$ & 0 & 1 & 2 & 3 & 4 \\
\hline $2,4,6,8,10$ & 4 & 3 & 2 & 1 & 0 \\
\hline
\end{tabular}

\subsection{Matrik Usability}

Metrik usability adalah kinerja pengguna yang mengacu pada tujuan kinerja yang spesifik untuk memenuhi tujuan usability. Metrik usability yang digunakan adalah:

- Scenario completion : tujuan scenario telah berhasil/selesai tanpa ada error.

- Critical errors : sebuah error yang menyebabkan task tidak selesai atau hasil yang salah.

- Non-critical Errors : error yang dapat diatasi oleh peserta atau, jika tidak terdeteksi, tidak berdampak pada tujuan task. 
- Evaluasi Subjektif untuk menilai kemudahan penggunaan web dan kepuasan pengguna yang dikumpulkan melalui kuesioner.

- Waktu penyelesaian skenario (time on task).

\subsection{Tujuan Usability}

Subbagian ini menjelaskan tentang tujuan usability web ecampus.stikomambon.ac.id yang mengacu pada metrik usability, yaitu antara lain.

- Completion rate: persentase jumlah peserta yang menyelesaikan task tanpa adanya critical error. Completion rate $100 \%$ adalah tujuan untuk setiap task.

- Error-free rate: persentase jumlah peserta yang dapat menyelesaikan tes tanpa mengalami error. Error-free rate $80 \%$ adalah tujuan untuk setiap task.

- Time on task (TOT): Waktu penyelesaian scenario. Setiap skenario penyelesaian adalah dua menit untuk skenario pencarian (akses halaman) dan empat menit untuk scenario lainnya.

- Subjective measures: Di akhir tes, peserta memberikan rating penilaian website secara keseluruhan.

\subsection{Desain Antarmuka E-Campus}

Prototipe e-Campus dibangun berdasarkan delapan prinsip pembuatan interface yang disebut golden rules (Shneiderman, 2010). Aturan/ prinsip-prinsip tersebut antara lain sebagai berikut:

1. Consistency. Terdapat beberapa bentuk konsistens, antara lain; Konsisten dalam hal urutan aksi untuk situasi-situasi yang mirip; terminologi yang identik digunakan untuk prompt, menu, dan halaman bantuan; dan konsisten dalam warna, layout, jenis tulisan, dan sebagainya.

2. Universal usability. Mengenali kebutuhan yang berbeda untuk tiap pengguna dan memfasilitasi transformasi konten. Misalnya, menambahkan fitur untuk pengguna pemula seperti penjelasan/bantuan, dan juga fitur untuk pengguna berpengalaman seperti shortcut dan akses cepat lainnya.

3. Feedback. Menawarkan feedback untuk setiap pengguna.

4. Dialog. Memberikan informasi terhadap proses terhadap aksi yang sedang dijalankan, agar user dapat mengetahui progres dari tahapan / proses yang dilakukan.
5. Prevent error. Sebisa mungkin, mendesain sistem yang dapat mencegah pengguna melakukan kesalahan serius. Jika pengguna membuat kesalahan, antarmuka harus dapat mendeteksi kesalahan tersebut dan menawarkan instruksi yang sederhana, kontruktif dan sepesifik sebagai jalan keluar.

6. Permit easy reversal of actions. Sebisa mungkin setiap aksi harus dapat dibalikkan (undo). Aksi pembalikan bisa berupa aksi tunggal, entry data, atau himpunan aksi lengkap.

7. Support internal locus of control. Sebisa mungkin membuat pengguna sebagai "inisiator aksi" bukan sebagai "responden terhadap aksi".

8. Redunce short-term memory load. Pembatasan pemrosesan informasi bagi pengguna. Tampilan dibuat sederhana agar memudahkan pengguna.

\section{HASIL DAN PEMBAHASAN}

$\mathrm{Bab}$ ini menyajikan hasil evaluasi berupa uji usability, post task overall questionnaries (system usability scale), dan rangkuman hasil open ended question.

\subsection{Uji Usability}

Hasil uji usability mengacu pada tujuan usability yang terdiri dari completion rate, errorfree rate, time on task, dan subjective measures. Task success rate (TSR): rata-rata jumlah peserta yang dapat menyelesaikan task. Formula untuk menghitungnya adalah sebagai berikut.

$$
T S R=\frac{\sum \text { Peserta }(\text { berhasil })}{\sum \text { Peserta }} \times 100 \%
$$

Hasilnya menggambarkan nilai fitur/fungsi tertentu dan juga antarmuka pengguna pada situs secara umum. Jumlah peserta yang berhasil dan persentasenya dapat dilihat pada Tabel 2 .

Tabel 2. Task completion rates \& success on time rates $(\mathrm{SoT})$

\begin{tabular}{|c|c|c|c|}
\hline $\begin{array}{c}\text { Task } \\
\text { Scenario }\end{array}$ & $\begin{array}{c}\text { Completion } \\
\text { Rates }\end{array}$ & Failed Rates & SoT rates \\
\hline Task 1 & $100 \%$ & $0 \%$ & $90 \%$ \\
\hline Task 2 & $100 \%$ & $0 \%$ & $95 \%$ \\
\hline Task 3 & $100 \%$ & $0 \%$ & $85 \%$ \\
\hline Task 4 & $85 \%$ & $15 \%$ & $45 \%$ \\
\hline Task 5 & $90 \%$ & $10 \%$ & $75 \%$ \\
\hline Task 6 & $90 \%$ & $10 \%$ & $80 \%$ \\
\hline Task 7 & $100 \%$ & $0 \%$ & $90 \%$ \\
\hline Task 8 & $100 \%$ & $0 \%$ & $65 \%$ \\
\hline Task 9 & $100 \%$ & $0 \%$ & $68 \%$ \\
\hline Task 10 & $100 \%$ & $0 \%$ & $80 \%$ \\
\hline Task 11 & $100 \%$ & $0 \%$ & $80 \%$ \\
\hline
\end{tabular}




\begin{tabular}{|c|c|c|c|}
\hline $\begin{array}{c}\text { Task } \\
\text { Scenario }\end{array}$ & $\begin{array}{c}\text { Completion } \\
\text { Rates }\end{array}$ & Failed Rates & SoT rates \\
\hline Task 12 & $100 \%$ & $0 \%$ & $80 \%$ \\
\hline Task 13 & $0 \%$ & $100 \%$ & $0 \%$ \\
\hline Task 14 & $60 \%$ & $40 \%$ & $35 \%$ \\
\hline Task 15 & $85 \%$ & $15 \%$ & $70 \%$ \\
\hline Task 16 & $100 \%$ & $0 \%$ & $90 \%$ \\
\hline Task 17 & $100 \%$ & $0 \%$ & $90 \%$ \\
\hline Task 18 & $0 \%$ & $100 \%$ & $0 \%$ \\
\hline Task 19 & $80 \%$ & $20 \%$ & $60 \%$ \\
\hline Task 20 & $60 \%$ & $40 \%$ & $15 \%$ \\
\hline Task 21 & $65 \%$ & $35 \%$ & $40 \%$ \\
\hline
\end{tabular}

Hasil pengujian pada Tabel 2 menunjukkan bahwa 10 dari 21 Task $(\sim 50 \%)$ tidak dapat diselesaikan peserta, artinya system e-Campus ${ }^{\mathrm{TM}}$ belum maksimal dalam memenuhi kebutuhan pengguna yang mengaksesnya. Lebih lanjut lagi, bahkan tidak terdapat task yang dapat diselesaikan tanpa error (error free) ataupun selesai tepat waktu (success on time). Faktanya setiap peserta membutuhkan waktu yang lebih ataupun bantuan (hint) untuk menyelesaikan setiap task.

Selain itu terdapat 2 task yang benar-benar tidak berfungsi (critical error) yaitu task 13 Pengisian form pengajuan proposal dan task 18 Pengajuan tempat PKL.

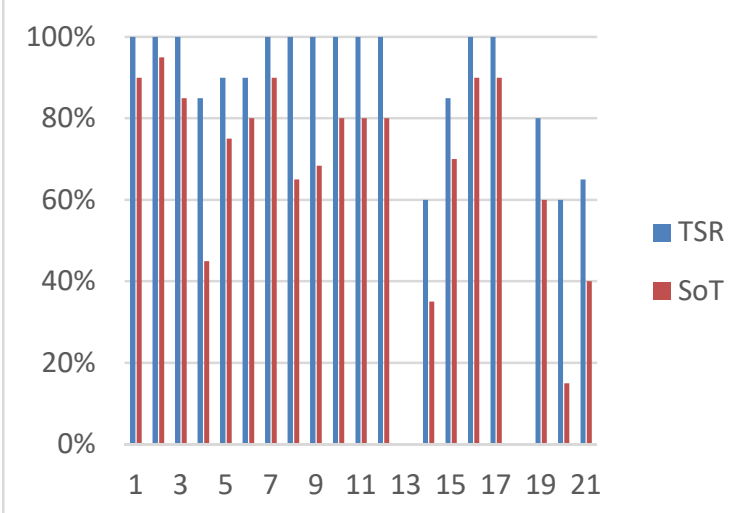

Gambar 1. Perbandingan jumlah peserta yang

berhasil menyelesaikan task (TSR) dengan jumlah peserta yang menyelesaikan tepat waktu (SoT) tanpa bantuan

Gambar 1 menunjukkan perbandingan persentase jumlah peserta yang berhasil menyelesaikan task (task success rate) dengan jumlah peserta yang menyelesaikan tepat waktu (success on time) tidak sama. Rata-rata perbedaannya adalah $\sim 18 \%$. Hal ini menunjukkan kurang efektifnya desaian/ antarmuka website dalam memberikan kemudahan bagi pengguna untuk memanfaatkan website.

\subsection{System Usability Scale}

Subbagian ini membahas pengukuran respon peserta secara subjektif terhadap website. Menggunakan metode SUS. Hasil survei peserta dapat dilihat pada Tabel 3. Rating mean menunjukkan rata-rata rating yang dipilih oleh peserta, dan dihitung menggunakan formula berikut ini.

$$
\overline{\text { ratıng }}=\frac{\sum(n(i) \times i)}{N}
$$

dimana $i=\{1,2,3,4,5\}$ adalah nilai rating, selanjutnya $n$ adalah jumlah peserta yang memilih rating $i$, sedangkan $N$ adalah total jumlah peserta. Selanjutnya persentase jumlah peserta yang setuju dihitung hanya berdasarkan jumlah peserta yang memilih nilai rating 4 (Setuju) dan nilai rating 5 (Sangat Setuju). Nilainya dihitung dengan persamaan berikut ini

$$
\text { Persentase setuju }=\frac{\sum n(j)}{N} \times 100 \%
$$

dimana nilai $j=\{4,5\}$ adalah nilai rating peserta yang setuju dan $n$ adalah jumlah peserta yang memilih rating $j$.

\begin{tabular}{|c|c|c|}
\hline $\begin{array}{l}\text { PTOQ } \\
(1-10)\end{array}$ & $\begin{array}{l}\text { Rating } \\
\text { Mean }\end{array}$ & $\begin{array}{l}\text { Persentase } \\
\text { Setuju }\end{array}$ \\
\hline $\begin{array}{l}\text { 1. Saya pikir bahwa saya akan } \\
\text { ingn lebih sering menggunakan } \\
\text { aplikasi ini }\end{array}$ & 2,9 & $25 \%$ \\
\hline $\begin{array}{l}\text { 2. Saya menemukan bahwa } \\
\text { aplikasi ini, tidak harus dibuat } \\
\text { serumit ini }\end{array}$ & 3,8 & $70 \%$ \\
\hline $\begin{array}{l}\text { 3. Saya pikir aplikasi mudah } \\
\text { untuk digunakan }\end{array}$ & 2,6 & $25 \%$ \\
\hline $\begin{array}{l}\text { 4. Saya pikir bahwa saya akan } \\
\text { membutuhkan bantuan dari } \\
\text { orang teknis untuk dapat } \\
\text { menggunakan aplikasi ini }\end{array}$ & 2,9 & $35 \%$ \\
\hline $\begin{array}{l}\text { 5. Saya meneukan berbagai fungsi } \\
\text { di aplikasi ini diintegrasikan } \\
\text { dengan baik }\end{array}$ & 2,9 & $30 \%$ \\
\hline $\begin{array}{l}\text { 6. Saya pikir ada terlalu banyak } \\
\text { ketidaksesuaian dalam aplikasi } \\
\text { ini }\end{array}$ & 3,6 & $65 \%$ \\
\hline $\begin{array}{l}\text { 7. Saya bayangkan bahwa } \\
\text { kebanyakan orang akan mudah } \\
\text { untuk mempelajari aplikasi ini } \\
\text { dengan sangat cepat }\end{array}$ & 2,2 & $15 \%$ \\
\hline $\begin{array}{l}\text { 8. Saya menemukan, aplikasi ini } \\
\text { sangat rumit untuk digunakan }\end{array}$ & 3,4 & $50 \%$ \\
\hline $\begin{array}{l}\text { 9. Saya merasa sangat percaya diri } \\
\text { untuk menggunakan aplikasi ini }\end{array}$ & 2,8 & $15 \%$ \\
\hline $\begin{array}{l}\text { 10. Saya perlu belajar banyak hal } \\
\text { sebelum saya bisa memulai } \\
\text { menggunakan aplikasi }\end{array}$ & 3,4 & $55 \%$ \\
\hline
\end{tabular}

Tabel 3. Nilai SUS 
Skor SUS dihitung berdasarkan petunjuk distribusi skor pada Tabel 1. Nilai skor SUS semua peserta telah dihitung, selanjutnya distribusi skor SUS setiap peserta dapat dilihat pada gambar berikut ini.

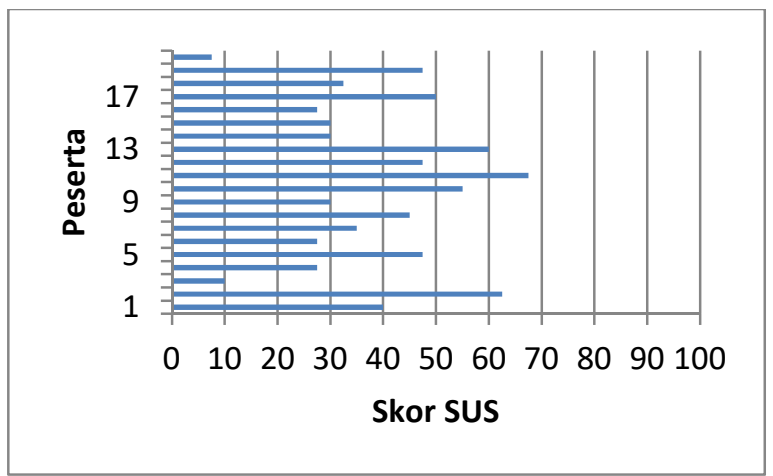

Gambar 2. Distribusi skor SUS para peserta

Dari grafik, terlihat bahwa kebanyakan peserta tidak menyukai memiliki nilai dibawah 50. Sehingga dapat disimpulkan bahwa antarmuka dan/atau fitur pada website penerimaan mahasiswa baru STIKOM Ambon sangat tidak baik. Hasil perhitungan menunjukkan bahwa dari 20 peserta tidak ada hasil penilaian $\geq 70$. Bahkan hanya terdapat $\sim 20 \%$ peserta memiliki nilai $>50 \%$. Hal ini menguatkan hasil uji usability dimana tidak terdapat peserta yang dapat meyelesaikan task tepat waktu ataupun tanpa error.

\subsection{Open-ended Question}

Pendapat secara umum terhadap situs eCampus Stikom Ambon lebih pada kekurangan yang dinilai, diantaranya:

- $100 \%$ participant berpendapat bahwa tampilan yang kurang menarik terhadap user interface mulai dari warna, icon, ukuran huruf maupun tata letak tombol yang ada.

- E-Campus STIKOM Ambon dinilai rumit ketika menggunakannya baik pengguna pemula maupun yang telah menggunkan situs tersebut sebelumnya.

- Tidak responsive.

Adapun saran yang diberikan terkait fiturfitur yang perlu ditambahkan, yaitu:

- Antar muka tampilan yang user friendly.

- Fitur pencarian yang difungsikan lebih luas lagi, bukan hanya pencarian pada menu.

- Adanya notifikasi ketika user melakukan kesalahan.
- Bantuan berupa video tutorial agar lebih mudah dipahami.

- Alur maupun fitur dibuat sesimpel mungkin.

- Fitur back dan next.

\subsection{Rancangan Desain Prototipe E-Campus}

Untuk itu diusulkan prototype untuk memperbaiki dan melengkapi fitur e-Campus STIKOM Ambon dengan mengkombinasikan golden rules shneiderman dan sejumlah masukan berdasarkan uji usability dan system usability scale.

\section{- Consistency}

Untuk memudahkan pengguna saat mengakses e-Campus, maka prototipe menggunakan 1 model layout standar untuk setiap halaman yang terdiri dari 2 menu navigasi (atas dan kiri) dan sebuah konten focal point utama. Layout dibuat sama untuk setiap halaman agar pengguna tidak bingung dan cepat beradaptasi saat mengakses setiap halaman. Contoh layout halaman e-Campus dapat dilihat pada Gambar 3. Selain itu, setiap kategori menu navigasi serta konten dibuat dengan warna yang kontras sehingga memudahkan pengguna dalam membaca informasi.

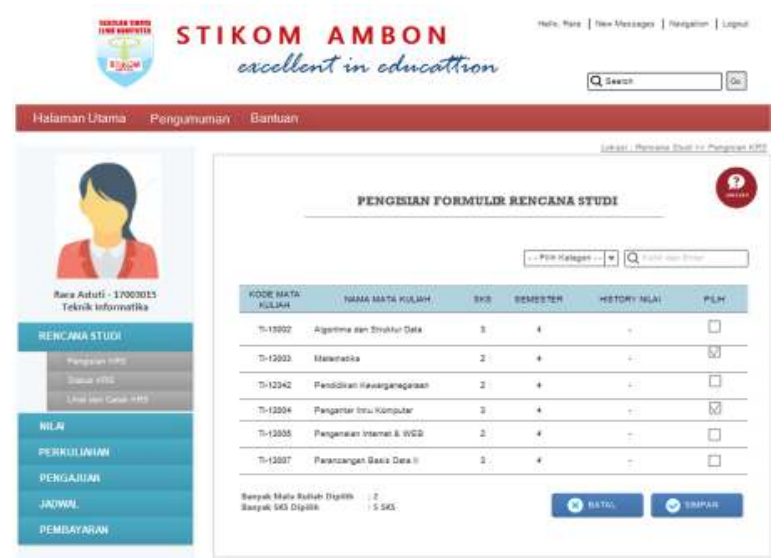

Gambar 3. Halaman pengisian rencana studi

\section{- Universal Usability}

Rancangan ini memfasilitasi transformasi konten/fitur. Artinya sebuah aksi tidak dibatasi hanya dengan sebuah tombol atau shortcut, tetapi terdapat opsi lain hint/ opsi lainnya untuk memudahkan pengguna pemula. Misalnya pada halaman Statistik Nilai pada Gambar 4 terdapat shortcut untuk menyimpan, mencetak, zoom-in, dan zoom-out, dan sebagainya, namun apabila user tidak familiar/paham dengan fungsi icon tetap akan terbantu dengan adanya keterangan teks untuk setiap icon. 


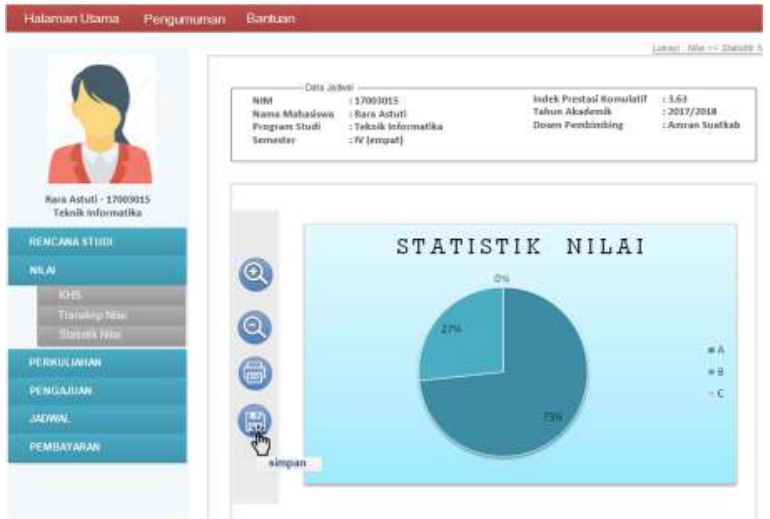

Gambar 4. Transformasi konten

\section{- Feedback}

Untuk tetap menjaga dan meningkatkan kepuasan pengguna disediakan laman khusus untuk memberikan masukan melalui pesan yang dapat diakses di bagian navigasi atas di setiap halaman e-Campus.

\section{STIKOM AMBON}

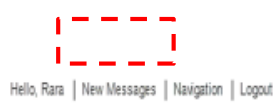

excellent in educatition

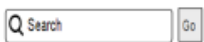

Gambar 5. Link untuk meninggalkan pesan/ feedback

Lebih lanjut, halaman pengisian pesan memungkinkan pengguna untuk menyampaikan keluhan yang bersifat kritis dan juga pesan/saran biasa. Pesan biasa bisa berupa saran untuk perbaikan ataupun untuk penambahan fitur baru dan lain sebagainya, sedangkan pesan kritis adalah jenis pesan yang harus segera ditindaklanjuti seperti halaman yang error, menu/link yang tidak berfungsi, ataupun informasi yang salah.

\section{- Dialog}

Setiap aksi pada fitur-fitur penting eCampus memungkinkan user untuk melihat status dari aksi yang dilakukan. Contohnya pada pesan terjadi kesalahan ataupun pesan berhasil melakukan penyimpanan data seperti tampak pada Gambar 6.

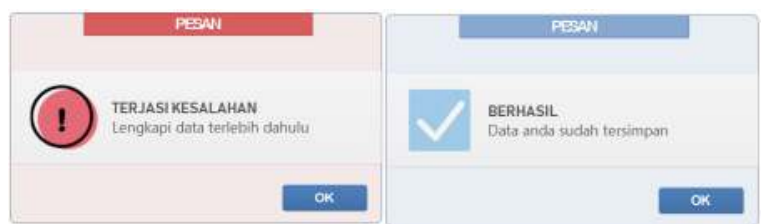

Gambar 6. Dialog untuk aksi penyimpanan data
- Prevent error

Prototipe dirancang agar sebisa mungkin pengguna tidak akan mengalami kesalahan serius. Jika pengguna membuat kesalahan, interface harus bisa mengidentifikasi error dan memberikan instruksi sederhana, kontruktif, dan spesifik untuk perbaikan. Misalnya mencegah terjadinya kesalahan unggah jenis dokumen yang ditetapkan ataupun melebihi kapasitas ukuran yang ditentukan. Contoh dan ilustrasi penanganan kesalahan dapat dilihat pada Gambar 7 , yang menunjukan bahwa jika dokumen yang diunggah bukan dengan ekstensi yang benar maka interface akan meminta user mengunggah dokumen baru yang tepat.
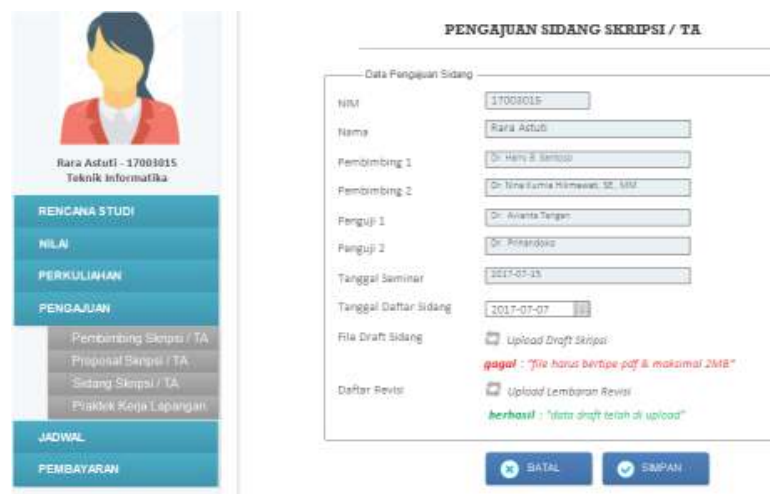

Gambar 7. Prevent Error pada form pengajuan siding

\section{- Reversal}

Prototipe yang dibangun juga menyertakan fitur reversal (kembali). Aksi reversal yang dibuat contohnya adalah tombol reset/batal pada form untuk mengosongkan setiap field seperti keadaan awal. Dan contoh lain dapat dilihat pada Gambar 8 tombol 'kembali' pada tampilan detail pengumuman yang berfungsi untuk kembali ke halaman pengumuman sebelumnya.

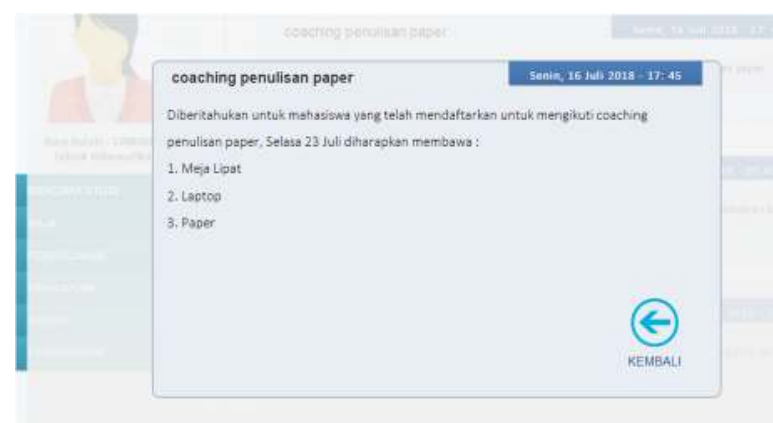

Gambar 8. Fitur reversal pada tampilan detail pengumuman

- Reduce short-term memory load 
Lebih lanjut lagi jumlah informasi yang ditampilkan pada sebuah halaman disesuaikan agar pengguna tidak terbebani (overload). Selain itu juga agar menjamin proses load sebuah halaman lebih cepat. Pada dasarnya, layout utama yang telah telah menjamin kesederhanaan tampilan yang akan memudahkan pengguna mengakses/membaca informasi. Sedangkan untuk halaman dengan jumlah kalimat/informasi banyak seperti pada halaman bantuan, dibuat inlink (anchor) agar dapat memudahkan navigasi pada setiap item dalam sebuah halaman. Ilustrasinya dapat dilihat pada Gambar 9.

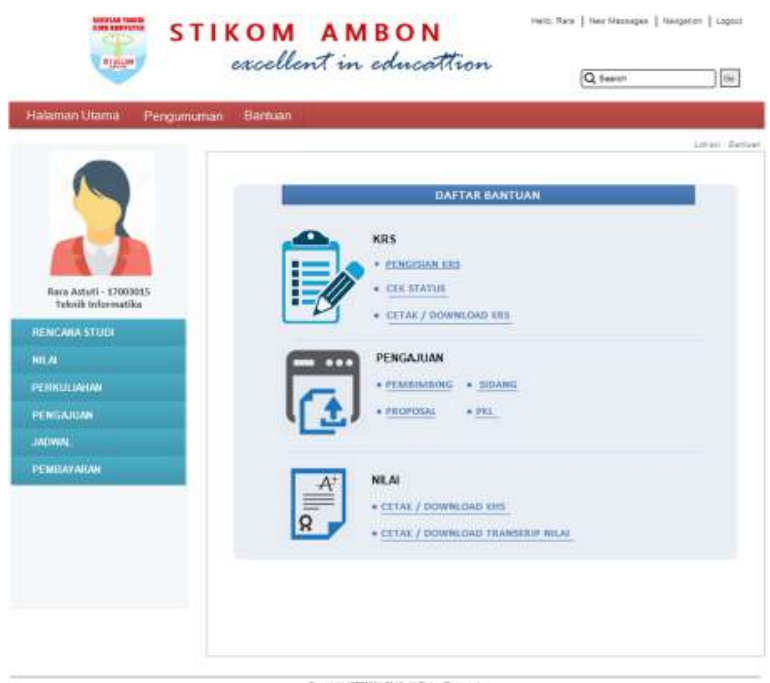

Gambar 9. Halaman bantuan

\section{PENUTUP}

\section{Kesimpulan}

System Usability Scale (SUS) memberikan gambaran umum penilaian peserta terhadap website. Hasil distribusi nilai SUS peserta menunjukkan hanya $\sim 10 \%$ peserta yang memiliki tingkat kepuasan di atas $50 \%$. Hal ini mendukung hasil uji usability yang telah dilakukan sebelumnya dimana tidak terdapat peserta yang dapat menyelesaikan task scenario tanpa error (error free) ataupun dalam kurun waktu yang disediakan (on time).

Selanjutnya setiap task scenario yang telah diuji dikombinasikan dengan open-ended question yang telah diajukan dirangkum sebagai masukan untuk diperhatikan pada tahap perancangan prototipe e-Campus. Lebih lanjut lagi untuk menjamin keberhasilan interface prototipe eCampus maka e-Campus dirancang dengan menggunakan prinsip-prinsip schneiderman (golden rules). Dengan memperhatikan setiap poinnya prototipe yang dibuat adalah memiliki fitur yang telah ditambah dan diperbarui dari eCampus sebelumnya dan juga tetap memperhatikan aspek kemudahan dan informatif bagi para pengguna.

\section{Saran}

Dilakukan evaluasi terhadap desain user interface yang dirancang, agar dapat mengetahui seberapa jauh tingkat kepuasan pengguna terhadap konten dan alternative desain antarmuka yang dirancang.

\section{REFERENSI}

Brooke, J., \& Et.al. (1996). SUS-A quick and dirty usability scale. Usability evaluation in industry, 189, 4-7.

Davis, D., \& Jiang, S. (2015, March). Usability evaluation of web-based interfaces for Type2 Diabetes Mellitus. In Industrial Engineering and Operations Management (IEOM), 2015 International Conference on (pp. 1-6). IEEE.

Jayanti, N. K. (2017). Kajian Analisa: Penerapan dan Pengembangan e-Government pada Pemerintah Propinsi Bali. Creative Information Technology Journal (CITEC Journal).

Mustafa, M. S., Ramadhan, M. R., \& Thenata, A. P. (2017). Implementasi Data Mining untuk Evaluasi Kinerja Akademik Mahasiswa Menggunakan Algoritma Naive Bayes Classifier. Creative Information Technology Journal (CITEC Journal).

Praningku, T., \& Budi, I. (2017). Sistem Prediksi Penyakit Kanker Serviks Menggunakan CART, Naive Bayes, dan k-NN. Creative Information Technology Journal (CITEC Journal).

Santoso, H. B., \& Fitriansyah, R. (2017). Prototype Development and Usability Evaluation of a Mobile-Based Arabic Language Learning Application. Journal of Engineering and Applied Sciences, 1961-1967.

Shneiderman, B. (2010). Designing the user interface: strategies for effective humancomputer interaction. Pearson Education India.

Sudarmawan, \& Ariyus, D. (2007). Interaksi Manusia \& Komputer. Yogyakarta: ANDI. 